\title{
Determination of Tributyltin in Seafood Based on Magnetic Molecularly Imprinted Polymers Coupled with High-Performance Liquid Chromatography-Inductively Coupled Plasma Mass Spectrometry
}

\author{
Hua Yang, ${ }^{1,2}$ Huien Zhang, ${ }^{2}$ Xiao Yan Zhu, ${ }^{1}$ Shi Da Chen, ${ }^{2}$ Lijun Liu, ${ }^{3}$ and Daodong Pan ${ }^{1}$ \\ ${ }^{1}$ School of Marine Sciences, Ningbo University, Ningbo 315121, China \\ ${ }^{2}$ Faculty of Biological and Environmental Science, Zhejiang Wanli University, Ningbo 315100, China \\ ${ }^{3}$ Weinan Entry-Exit Inspection and Quarantine Bureau, Shaanxi 714000, China \\ Correspondence should be addressed to Daodong Pan; pandaodong@nbu.edu.cn
}

Received 25 August 2016; Accepted 20 December 2016; Published 21 February 2017

Academic Editor: Egidio De Benedetto

Copyright @ 2017 Hua Yang et al. This is an open access article distributed under the Creative Commons Attribution License, which permits unrestricted use, distribution, and reproduction in any medium, provided the original work is properly cited.

\begin{abstract}
In this study, $\mathrm{Fe}_{3} \mathrm{O}_{4}$ was adopted as a carrier for surface molecular imprinting with two-stage polymerization. First, the functional monomer (methacrylic acid, MAA) was modified on the surface of $\mathrm{Fe}_{3} \mathrm{O}_{4}$, which was then polymerized with the template molecule (tributyltin, TBT), cross linking agent (ethylene glycol dimethacrylate, EGDMA), and porogen (acetonitrile), hereby successfully preparing $\mathrm{Fe}_{3} \mathrm{O}_{4} @ M I P s$ prone to specifically identify TBT. The physical properties of $\mathrm{Fe}_{3} \mathrm{O}_{4} @ \mathrm{MIPs}$ were then characterized, and adsorption and selection capacities were also assessed. Compared with conventional imprinting polymers, this magnetic molecular imprinting polymer (MIP) displayed significantly increased and more specific adsorption. Meanwhile, its pretreatment was simpler and faster due to magnetic separation characteristics. Using magnetic MIPs as adsorbents for enrichment and separation, detection limit, recovery rate, and linear range were $1.0 \mathrm{ng} \mathrm{g}^{-1}, 79.74-95.72 \%$, and $5 \mathrm{ng} \mathrm{g}^{-1} \sim 1000 \mathrm{ng} \mathrm{g}^{-1}$, respectively, for a number of seafood samples. High-performance liquid chromatography-inductively coupled plasma mass spectrometry (HPLC-ICP-MS) was used to analyze Tegillarca granosa, mussels, large yellow croaker, and other specimens, with recovery rates of 79.74-95.72\% and RSD of $1.3 \%-4.7 \%$. Overall, this method has a shorter total analysis time, lower detection limit, and wider linear range and can be more effectively applied to determine MAA in seawater and seafood.
\end{abstract}

\section{Introduction}

Organic tin compounds show very good reactivity and biological activity and are widely used in various fields of industry and agriculture, for example, as antifoulant additives for naval vessels $[1,2]$, biocides and bactericides [3], and plastic stabilizers [4]. Due to their widespread application, large amounts of toxic organic tin compounds have entered the environmental ecosystem through various ways, causing damage to the ecosystem [5]. In particular, global water pollution caused by marine antifoulant coatings containing TBT is persistent but also greatly harms marine life and human health through biological accumulation [6]. Thus, TBT is considered one of the most toxic substances introduced into the marine environment [7]. For example, a TBT content of $1 \mathrm{ng} / \mathrm{L}$ in seawater induces sexual aberrations in gastropods $[8,9] ; 1 \sim 20 \mathrm{ng} / \mathrm{L}$ TBT is prone to interfere with the breeding of planktons and shellfishes, while $1 \sim 1000 \mu \mathrm{g} / \mathrm{L}$ can affect breeding and even cause behavioral disorders in fish [10]. Thus, it is important to develop a highly sensitive and selective detection method to rapidly and efficiently assess microscale organotin.

Currently, various methods have been proposed for organotin detection, including gas chromatography-mass spectrometry (GC-MS) [11], gas chromatography-flame photometric detection (GC-FPD) [12], gas chromatographyatomic adsorption spectroscopy (GC-AAS) [13], and gas 
chromatography-microwave induced plasma atomic emission spectroscopy (GC-MIP-AES) [14]. These techniques are irreplaceable in the detection of organic compounds and have been widely used in morphological analysis. However, some of them have low sensitivity and are inappropriate for organotin analysis. Compared to the above methods, HPLC combination technique does not require derivatization procedures. In addition, instrument combination has achieved a great breakthrough in recent years, for example, high-performance liquid chromatography-atomic adsorption spectroscopy (HPLC-AAS) [15, 16], high-performance liquid chromatography-mass spectrometry (HPLC-MS) [15, 16], and high-performance liquid chromatography-induced coupled plasma atomic emission spectrometry (HPLC-ICPAES) [17]. Nevertheless, some problems remain, including flow rate mismatch and narrow mobile phase. Meanwhile, HPLC-ICP-MS $[18,19]$ has advantages of liquid chromatography (e.g., no need for derivatization, simplicity and rapidness, and good separation outcome) and also technical superiorities of ICP-MS, including broad application, high sensitivity, low detection limit, low background interference, wide linear range, good stability, as well as long-term resistance to organic mobile phase. Thus, HPLC-ICP-MS is highly sensitive in assessing organic tin compounds and does not require derivatization.

Polymers prepared by the molecular imprinting technique (MIT) [20] are called molecular imprinting polymers (MIPs). MIT can be vividly depicted as a technique to manufacture "artificial lock" for "molecular key" identification [21]. It is a novel affinity separation technique, which provides a new tool to prepare separation medium, with good development potential. It has been widely applied in enrichment and separation, chiral resolution, drug testing, environmental sample analysis, catalysis, sensors, and other fields [22]. Wang et al. [23] utilized MIT products synthetized by non-covalent molecular imprinting in selective solidphase extraction of organochlorine pesticides in marine biological samples, with recovery rates of $85.8 \% \sim 101.2 \%$. Meanwhile, Liu et al. [24] applied MIP to preconcentrate serous herbicide, achieving an extraction time of only $30 \mathrm{~min}$. Zhang et al. [25] utilized magnetic MIPs to concentrate and analyze triazine herbicides in vegetables and obtained recovery rates of $71.6 \% \sim 126.7 \%$, that is, about 100 times their original concentrations.

In-depth analysis of MIP has revealed some deficiencies for conventional molecular imprinting materials, such as difficult binding of template molecules and binding loci, low balance rate, and poor controllability in the grinding process. Therefore, researchers currently focus on developing MIP preparation, using water phase imprinting, electropolymerization, micro-nano imprinting, and magnetic molecular imprinting.

Magnetic adsorption is a newly developed technique, which is applicable to treat pollutants in air and wastewater; it has gained widespread application [26-31]. Adsorbents are easily separated using an external magnetic field and are thus suitable for large-scale dynamic adsorption. The magnetized adsorbents are permanently magnetic, with the following benefits when applying for separation: (1) fast, efficient, and reusable; (2) simple operation, without requiring expensive equipment; (3) unlikelihood to influence the substances to be separated, especially for biological molecules, which should maintain their physiological activities. According to materials to be separated, particles are usually modified to provide them with active groups or specific antibodies, followed by their input into the solution to be separated, stirring, and ultimately adding an external magnetic field to separate the magnetic particles from the solution, which can be reused [32]. Magnetic MIPs are polymeric microspheres with paramagnetic and MIP properties that combine inorganic magnetic materials and the molecular imprinting technique. Meanwhile, the magnetic separation technique is a relatively new separation tool, where magnetic support bodies are controllable with respect to the imprinting polymers; this tends to provide faster and simpler separation compared with the conventional molecular imprinting centrifugation separation (Ke et al. 2011).

In this study, we attempted to develop a new method to determine TBT in marine products. We first prepared magnetic MIPs and studied their properties. Then, the magnetic MIPs were utilized as the adsorbent to concentrate TBT, which was detected by HPLC-ICP-MS, hereby shortening the analysis time.

\section{Materials and Methods}

2.1. Main Reagents and Instruments. Main reagents included 96\% tributyltin (TBT), 95\% monobutyltin (MBT), 97\% dibutyltin (DBT), 96\% triphenyltin (TPhT), methacrylic acid (MAA), ethylene glycol dimethacrylate (EGDMA), 98\% azodiisobutyronitrile (AIBN), HPLC-grade methanol, HPLC-grade ethanol, trimethylamine, and acetonitrile (Sigma-Aldrich Co., Shanghai, China). Ultrapure water was produced with the Milli-Q ultrapure water system (resistivity, $18.2 \mathrm{M} \Omega \mathrm{cm}$ ). Main instruments were 1100 highperformance liquid chromatography (Agilent, Palo Alto, United States); 7500ce plasma mass spectrometer (Agilent, Palo Alto, United States); Discovery C18, $150 \mathrm{~mm} \times 4.6 \mathrm{~mm}$, $5 \mu \mathrm{m}$ column (Supelco Co. Ltd., Bellefonte, United States); ZM200 grinder (Retsch, Hanau, Germany); SHA-C stable temperature oscillator (Changzhou Guohua Instrument Factory, Guangzhou, China); BiofugePrimo R 7500 tabletop refrigerated centrifuge (Heraeus, Hanau, Germany); MG2200 nitrogen blowing instrument (Tokyo Rikakikai Co. Ltd., Bunkyo-ku, Japan); JEM-1011 transmission electron microscope (Jeol Co. Ltd., Akishima, Japan); D8Advancde X-ray diffractometer (Bruker-AXS, Karlsruhe, Germany); Nicolet6700 Fourier transform infrared spectroscopy (Thermo, Waltham, United States); and vibrating sample magnetometer (Lake shore, Westerville, United States).

Specimens included Tegillarca granosa, mussels, and large yellow croaker that were purchased from Ningbo Lulin Market (500 g, Ningbo, China) and to get rid of internal 
organs and other inedible parts, the remaining portion was cleaned, dried, and frozen at $-20^{\circ} \mathrm{C}$.

\subsection{Experimental Methods}

2.2.1. Preparation of Magnetic Molecular Imprinting Polymers. $\mathrm{Fe}_{3} \mathrm{O}_{4}$ nanoparticles were prepared as previously described [32]: briefly, $4.7 \mathrm{~g} \mathrm{FeCl}_{3} \cdot 6 \mathrm{H}_{2} \mathrm{O}$ and $3.9 \mathrm{~g} \mathrm{Fe}\left(\mathrm{NH}_{4}\right)_{2}\left(\mathrm{SO}_{4}\right)_{2} \cdot 6 \mathrm{H}_{2} \mathrm{O}$ were added to a $500 \mathrm{~mL}$ boiling flask-3-neck and mixed with $200 \mathrm{~mL} 0.1 \mathrm{~mol} \mathrm{~L}^{-1}$ hydrochloride solution, with mechanical stirring. Afterward, the system was rapidly supplemented with $3 \mathrm{~mol} / \mathrm{L}$ sodium hydroxide to obtain $\mathrm{pH}>9$, which resulted in immediate color change from yellow to black. Then, the temperature was increased to $80^{\circ} \mathrm{C}$ for $1 \mathrm{~h}$. When the temperature was restored to room temperature, the products were separated using magnets, collected, rinsed with redistilled water, and dried under vacuum for subsequent experiments.

In two-stage polymerization, MAA (as functional units) was modified onto the surface of $\mathrm{Fe}_{3} \mathrm{O}_{4}$ nanoparticles: first, $100 \mathrm{mg} \mathrm{Fe}_{3} \mathrm{O}_{4}$ nanoparticles were dissolved into $150 \mathrm{~mL}$ aqueous ethanol solution ( $\mathrm{v} / \mathrm{v}, 14: 1)$, followed by gradual dripping with $50 \mu \mathrm{L}$ APTS and stirring at room temperature for $7 \mathrm{~h}$. Then, the products were separated using external magnetic field, followed by 5 ethanol rinses and drying under vacuum to obtain $\mathrm{Fe}_{3} \mathrm{O}_{4} @$ APTS particles [33]. Meanwhile, APTS modified magnetic nanoparticles were reacted with excessive methacrylic acid in methanol at $25^{\circ} \mathrm{C}$ for $24 \mathrm{~h}$, followed by separation with magnets, rinsing with ethanol, and drying under vacuum, hereby yielding $\mathrm{Fe}_{3} \mathrm{O}_{4} @ \mathrm{MAA}$ [34].

For molecular imprinting polymerization, magnetic particles coated with a layer of MIP were prepared. $\mathrm{Fe}_{3} \mathrm{O}_{4} @ \mathrm{MAA}$ particles $(100 \mathrm{mg})$ and TBT $(1 \mathrm{mmol})$ were dissolved into $40 \mathrm{~mL}$ acetonitrile, stirred at room temperature for $6 \mathrm{~h}$, and supplemented with EGDMA (22 mmol) and AIBN $(15 \mathrm{mg})$. This was followed by ultrasonication in ice bath bubbled with nitrogen for $5 \mathrm{~min}$, stirring at $50^{\circ} \mathrm{C}$ for $5 \mathrm{~h}$, polymerization at $65^{\circ} \mathrm{C}$ for $20 \mathrm{~h}$, and aging at $85^{\circ} \mathrm{C}$ for $5 \mathrm{~h}$. The particles were ultimately separated, rinsed with methanol dichloromethane solution (v/v, $4: 1)$ for 5 times, and extracted with $0.3 \mathrm{~mol} / \mathrm{L}$ sodium hydroxide methanol as eluent using the Soxhlet method, until no template molecule TBT contained the polymer. Finally, the products were separated and dried under vacuum to obtain TBT coated magnetic MIPs $\left(\mathrm{Fe}_{3} \mathrm{O}_{4} @ \mathrm{MIPs}\right)$, which would be used for enrichment and separation analysis.

Magnetic MIP controls $\left(\mathrm{Fe}_{3} \mathrm{O}_{4} @ \mathrm{NIPs}\right)$ were prepared using the abovementioned method, except for adding the imprinting molecule TBT.

2.2.2. Determination of Adsorption (Q). $20 \mathrm{mg} \mathrm{Fe}{ }_{3} \mathrm{O}_{4} @ M I P s$ or $\mathrm{Fe}_{3} \mathrm{O}_{4} @$ NIPs were added to the TBT solution and incubated with shaking at room temperature for $10 \mathrm{~h}$. Then, the TBT concentration in the supernatant was determined using HPLC-ICP-MS, and adsorption $Q$ was derived by the

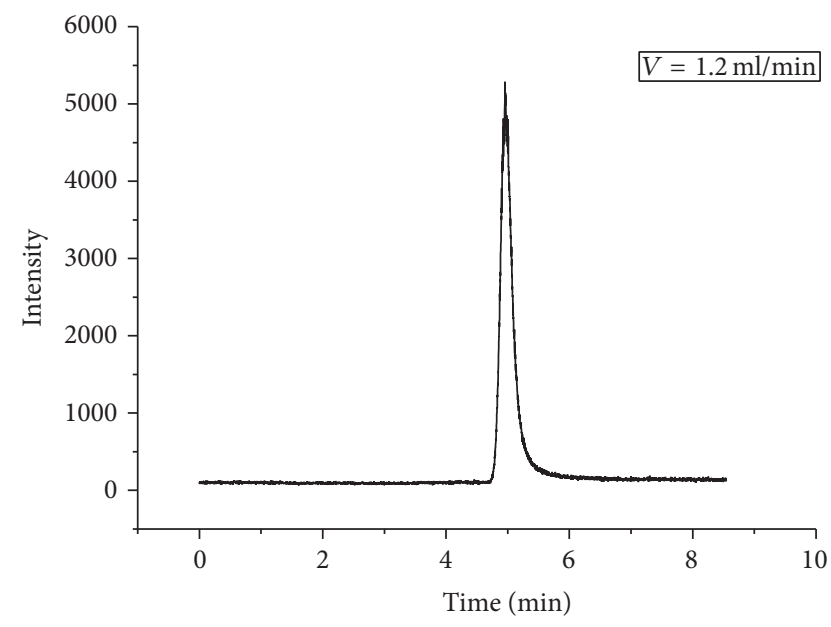

Figure 1: HPLC-ICP-MS spectrum for TBT standard substance (flow rate $1.2 \mathrm{~mL} / \mathrm{min}$ ).

following formula according to changes of TBT concentration before and after adsorption [34]:

$$
Q=\frac{\left(C_{0}-C\right) V}{W},
$$

where $Q$ is the adsorption $\left(\mu \mathrm{g} \mathrm{g}^{-1}\right) ; C_{0}$ and $C$ are TBT concentrations before and after adsorption, respectively $\left(\mu \mathrm{g} \mathrm{L}^{-1}\right) ; W$ is dry polymer weight (mg); and $V$ refers to solution volume (L).

\subsubsection{Detection of TBT Using HPLC-ICP-MS. SUPELCO} Discovery C18 column $(15 \mathrm{~cm} \times 4.6 \mathrm{~mm}, 5 \mu \mathrm{m})$ was adopted and manually tuned using $10 \mu \mathrm{g} \mathrm{L}^{-1}$ tuning liquid to ensure that sensitivity, mass number, oxides, electric double layer, and other indicators met the requirements. Methanol-water equal to $70: 30(\mathrm{v} / \mathrm{v})$ was used as mobile phase at a flow rate of $1.2 \mathrm{~mL} / \mathrm{min}$; injection volume was $20 \mu \mathrm{L}$, and the TBT peak is shown in Figure 1.

2.2.4. $\mathrm{Fe}_{3} \mathrm{O}_{4} @ M I P s$ Synthesis Conditions. For eluent selection, 20 mg Fe $\mathrm{O}_{4} @$ MIPs were added to $20 \mu \mathrm{g} \mathrm{L}^{-1}$ TBT solution, which was stirred for $10 \mathrm{~h}$. Then, formic acid, acetic acid, sodium hydroxide, and ammonia were mixed to obtain different concentrations of methanol dichloromethane, which was used to eluate TBT adhering to $\mathrm{Fe}_{3} \mathrm{O}_{4} @ M I P s$; elution amount was determined. Of all solvents, methanol dichloromethane, with the optimal elution effect, would be selected for subsequent assays.

For elution time selection, 5 shares of $20 \mathrm{mg} \mathrm{Fe}_{3} \mathrm{O}_{4} @ \mathrm{MIPs}$ were separately added to $20 \mu \mathrm{g} \mathrm{L}^{-1}$ TBT solution, which was stirred to adsorb for $10 \mathrm{~h}$. Then, the eluent selected using the abovementioned method was applied, and the amounts of TBT eluted from $\mathrm{Fe}_{3} \mathrm{O}_{4} @ M I P s$ with different times were determined; of these, an elution time yielding an optimal elution effect would be selected for subsequent assays.

2.2.5. Characterization Methods. $\mathrm{Fe}_{3} \mathrm{O}_{4}$ and $\mathrm{Fe}_{3} \mathrm{O}_{4} @ \mathrm{MIPs}$ dried under vacuum were placed on a microgrid and 
TABLE 1: Elution rate of TBT from $\mathrm{Fe}_{3} \mathrm{O}_{4} @$ MIPs with different $\mathrm{pH}$ concentrations of eluents.

\begin{tabular}{lllllllllcrcr}
\hline Eluent & \multicolumn{1}{l}{ Formic acid methanol } & \multicolumn{1}{l}{ Acetic acid methanol solution } & Sodium hydroxide methanol & \multicolumn{2}{c}{ Ammonia methanol } \\
\hline Concentration (M) & 0.05 & 0.1 & 0.5 & 0.05 & 0.1 & 0.5 & 0.05 & 0.1 & 0.5 & 0.05 & 0.1 & 0.5 \\
Elution rate (\%) & 56.3 & 96 & 83 & 42 & 80.6 & 69.8 & 41 & 46 & 56.7 & 40 & 70 & 79.8 \\
\hline
\end{tabular}

characterized on a JEM-1011 transmission electron microscope (TEM). Then, powder samples $\left(\mathrm{Fe}_{3} \mathrm{O}_{4}, \mathrm{Fe}_{3} \mathrm{O}_{4} @ M A A\right.$, and $\left.\mathrm{Fe}_{3} \mathrm{O}_{4} @ \mathrm{MIPs}\right)$ were dried under vacuum and analyzed for their structure on a Bruker D8 X-ray diffractometer (XRD). For FTIR characterization, powder samples $\left(\mathrm{Fe}_{3} \mathrm{O}_{4}\right.$, $\mathrm{Fe}_{3} \mathrm{O}_{4} @ \mathrm{APTS}, \mathrm{Fe}_{3} \mathrm{O}_{4} @ \mathrm{MAA}$, and $\left.\mathrm{Fe}_{3} \mathrm{O}_{4} @ \mathrm{MIPs}\right)$ were dried under vacuum and separately mixed with $\mathrm{KBr}$ (mass ratio of $1: 4$ ) under an infrared lamp, followed by squashing and characterization with Nicolet6700 Fourier transform infrared spectroscopy. Finally, the magnetic properties of $\mathrm{Fe}_{3} \mathrm{O}_{4}$ and $\mathrm{Fe}_{3} \mathrm{O}_{4} @ \mathrm{MIPs}$ were assessed using a vibrating sample magnetometer (VSM).

\subsubsection{Properties of $\mathrm{Fe}_{3} \mathrm{O}_{4} @ M I P s$}

Selection Distinctiveness Test. $20 \mathrm{mg} \quad \mathrm{Fe}_{3} \mathrm{O}_{4} @ \mathrm{MIPs}$ and $\mathrm{Fe}_{3} \mathrm{O}_{4} @$ NIPs were added to four types of $50 \mu \mathrm{g} \mathrm{L}-1$ organotin (MBT, DBT, TBT, and TPhT) solutions, respectively, with ethanol as solvent, followed by stirring adsorption for $10 \mathrm{~h}$. Then, the concentrations of residual organotin were assessed by HPLC-ICP-MS, for adsorption calculation.

Adsorption Dynamics Test. $20 \mathrm{mg} \quad \mathrm{Fe}_{3} \mathrm{O}_{4} @ \mathrm{MIPs}$ and $\mathrm{Fe}_{3} \mathrm{O}_{4} @$ NIPs were placed into each of six $10 \mathrm{~mL}$ beakers containing $20 \mu \mathrm{gL}^{-1}$ TBT solution, followed by stirring adsorption for $10,20,30,60,120$, and $180 \mathrm{~min}$, respectively. Then, the concentrations of residual TBT were assessed by HPLC-ICP-MS, hereby determining the adsorption rate.

Adsorption Isotherm Test. $20 \mathrm{mg} \quad \mathrm{Fe}_{3} \mathrm{O}_{4} @ M I P s$ and $\mathrm{Fe}_{3} \mathrm{O}_{4} @$ NIPs were separately added to TBT solutions to yield concentrations of 10, 20, 40, 70, 90, 150, and $300 \mu \mathrm{g} \mathrm{L}^{-1}$ and stirred for $10 \mathrm{~h}$. Then, residual TBT concentrations were determined by HPLC-ICP-MS, to calculate adsorption.

Regenerability of $\mathrm{Fe}_{3} \mathrm{O}_{4} @ M I P s .20 \mathrm{mg} \mathrm{Fe}_{3} \mathrm{O}_{4} @ \mathrm{MIPs}$ were added to $20 \mu \mathrm{g} \mathrm{L}^{-1}$ TBT solution, followed by stirring adsorption for $10 \mathrm{~h}$ and elution. Then, residual TBT amounts in the solution were evaluated by HPLC-ICP-MS to calculate the adsorption rate. Afterwards, the eluted MIPs were dried under vacuum and recovered. The above procedures were repeated 5 times.

2.2.7. Preparation of Specimens. Three specimens of $0.1 \mathrm{~g}$ frozen marine product tissues (Tegillarca granosa, mussels, large yellow croaker) were separately placed into $10 \mathrm{~mL}$ centrifuge tubes; in two of them, $100 \mu \mathrm{L}$ standard TBT solutions at concentrations of 50 and $100 \mu \mathrm{g} \mathrm{L}^{-1}$, respectively, were added, to yield 5 and $10 \mathrm{ng}$ TBT (adding standard
TABLE 2: Time effect on elution rate of TBT with polymers.

\begin{tabular}{lccccc}
\hline Polymer elution time (h) & 0.5 & 1 & 2 & 3 & 4 \\
Elution rate (\%) & 46 & 70.3 & 88.7 & 90 & 91.6 \\
\hline
\end{tabular}

matter amount of $50 \mathrm{ngg}^{-1}$ and $100 \mathrm{ng} \mathrm{g}^{-1}$, resp.). Tissues added with standard matter were oscillated for $1 \mathrm{~h}$ and incubated overnight with no shaking. Then, TBT in marine product tissues was extracted by ultrasound for $30 \mathrm{~s}$, with $5 \mathrm{~mL}$ acetic acid methanol solution (volume ratio: $1: 1$ ) as extract buffer (frequency about $35 \mathrm{KHz}$ ). This was followed by centrifugation ( $4000 \mathrm{rpm}, 3 \mathrm{~min}$ ), and the supernatant was collected. Afterward, the above extraction procedures were repeated once, and supernatants from both extractions $(10 \mathrm{~mL})$ were combined and diluted with $50 \mathrm{~mL}$ ultrapure water. $20 \mathrm{mg}$ conventional imprinting polymers were added to this mixture and stirred using magnetic force, followed by centrifugation. Finally, $6 \mathrm{~mL} 0.1 \mathrm{M}$ formic acid methanol solution was used to elute TBT, which was adsorbed on the polymer; the eluent was evaporated using nitrogen blowing instrument and adjusted to $1 \mathrm{~mL}$ with aqueous methanol solution (volume ratio $70: 30$ ). After filtration with $0.45 \mu \mathrm{m}$ organic filtration membrane, the samples were submitted to subsequent HPLC-ICP-MS analysis.

\section{Results and Discussion}

\section{1. $\mathrm{Fe}_{3} \mathrm{O}_{4} @ M I P$ Synthesis Conditions}

3.1.1. Selection of Eluent. Formic acid, acetic acid, sodium hydroxide, and ammonia were used to formulate different concentrations of methanol dichloromethane solution, which was used to eluate TBT adsorbed on $\mathrm{Fe}_{3} \mathrm{O}_{4} @ \mathrm{MIPs}$, hereby deriving elution amounts, as shown in Table 1.

As shown in Table 1, an appropriate $\mathrm{pH}$ may make it easier to elute TBT, while an excessively high $\mathrm{pH}$ may decrease the elution rate. In addition, acid solutions showed a better elution effect compared with alkaline counterparts, while weakly acidic solutions showed a better elution effect compared to strongly acidic solutions. Therefore, $0.1 \mathrm{M}\left(\mathrm{mol} \mathrm{L}^{-1}\right)$ formic acid methanol solution was selected as eluent.

3.1.2. Selection of Elution Time. After $20 \mu \mathrm{gL}^{-1}$ TBT was adsorbed for $10 \mathrm{~h}$ using $\mathrm{Fe}_{3} \mathrm{O}_{4} @$ MIPs, elution was carried out with $0.1 \mathrm{M}\left(\mathrm{mol} \mathrm{L}^{-1}\right)$ formic acid methanol solution, and results are shown in Table 2.

As shown in Table 2, elution time affected TBT elution volume in $\mathrm{Fe}_{3} \mathrm{O}_{4} @$ MIPs. Short elution times led to small 


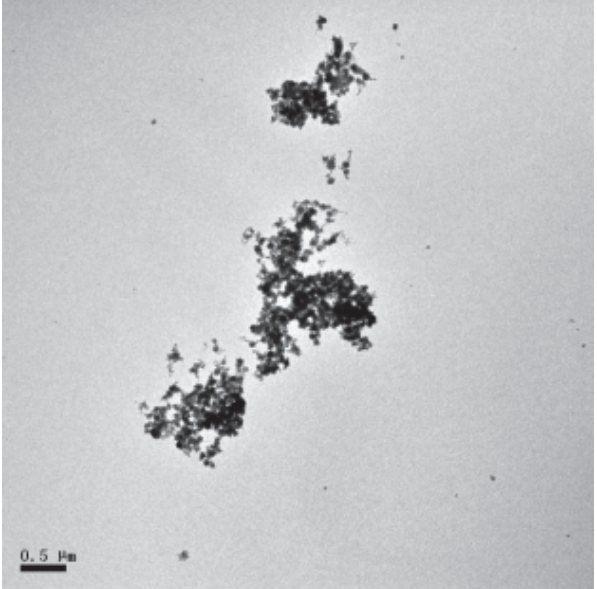

(a)

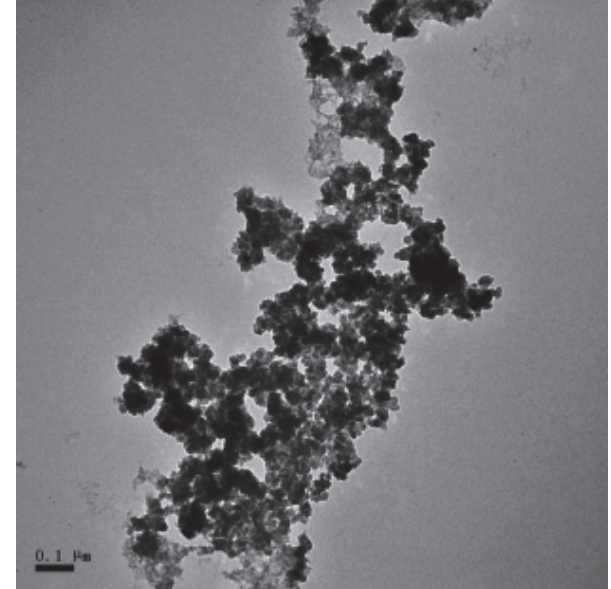

(b)

FIGURE 2: TEM of $\mathrm{Fe}_{3} \mathrm{O}_{4}$ nanoparticles (a) and $\mathrm{Fe}_{3} \mathrm{O}_{4} @ M I P s$ particles (b).

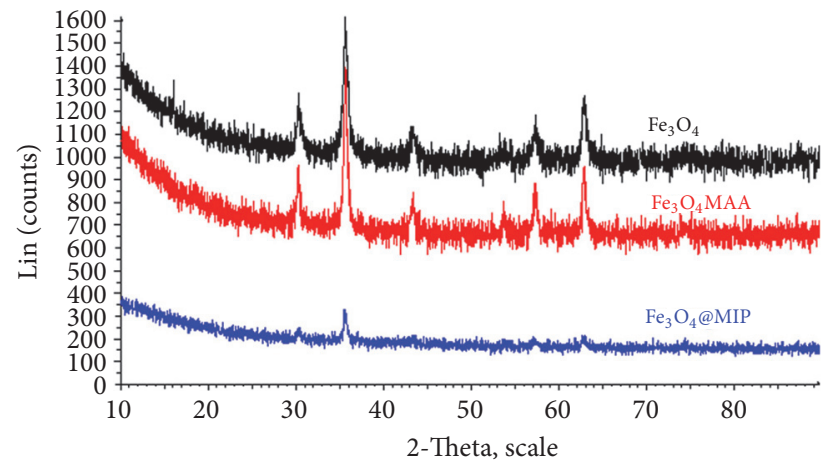

FIGURE 3: XRD of magnetic particles.

elution volumes, which may be explained by the fact that the eluent did not fully contact TBT. With increasing elution time, the eluent fully contacts TBT, thereby leading to increased elution volumes. Meanwhile, after $2 \mathrm{~h}$, elution volumes did not change significantly, which indicates that TBT in the $\mathrm{Fe}_{3} \mathrm{O}_{4} @$ MIPs was basically eluted. Therefore, $2 \mathrm{~h}$ was selected as elution time for subsequent assays.

\subsection{Characterization}

3.2.1. TEM Characterization. As shown in Figure 2, the diameters of $\mathrm{Fe}_{3} \mathrm{O}_{4} @$ MIPs nanoparticles were larger than those of $\mathrm{Fe}_{3} \mathrm{O}_{4}$ nanoparticles, probably because $\mathrm{Fe}_{3} \mathrm{O}_{4} @ M I P s$ are coated with an MIP layer. In addition, because the MIP layer has binding sites that can specifically adsorb TBT, $\mathrm{Fe}_{3} \mathrm{O}_{4} @ \mathrm{MIPs}$ also have specific adsorption capacity.

3.2.2. XRD Characterization. Figure 3 shows the $\mathrm{X}$ ray diffraction patterns of $\mathrm{Fe}_{3} \mathrm{O}_{4}, \mathrm{Fe}_{3} \mathrm{O}_{4} @ M A A$, and $\mathrm{Fe}_{3} \mathrm{O}_{4} @$ MIPs particles. It can be observed that the positions

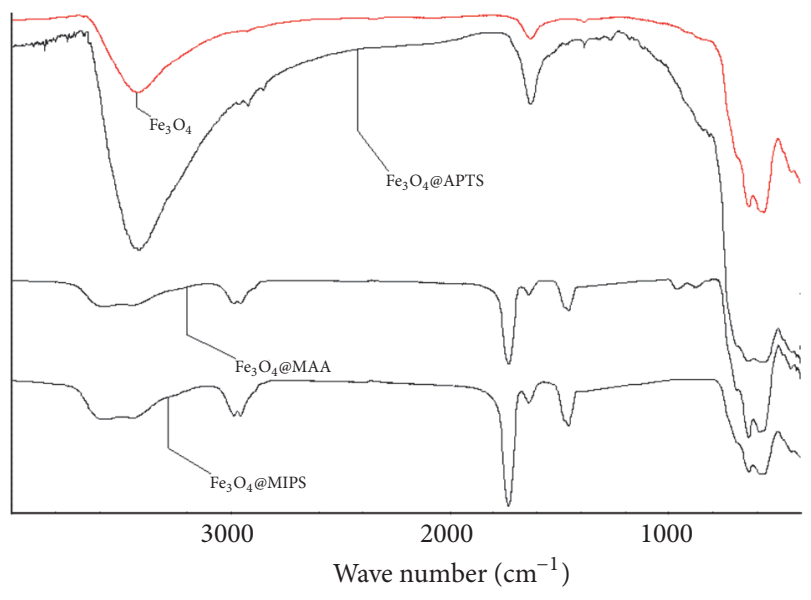

FIgURE 4: The FTIR of magnetic particles.

of their characteristic peaks remained the same, indicating that $\mathrm{Fe}_{3} \mathrm{O}_{4} @$ MIPs are unlikely to alter the crystal structure $[35,36]$. Meanwhile, peak intensity of $\mathrm{Fe}_{3} \mathrm{O}_{4} @$ MIPs particles was weaker than those of $\mathrm{Fe}_{3} \mathrm{O}_{4}$ and $\mathrm{Fe}_{3} \mathrm{O}_{4} @ M A A$ particles, likely because $\mathrm{Fe}_{3} \mathrm{O}_{4} @$ MIPs particles are coated with an MIP layer.

3.2.3. FTIR Characterization. Figure 4 displays FTIRs of $\mathrm{Fe}_{3} \mathrm{O}_{4}, \mathrm{Fe}_{3} \mathrm{O}_{4} @ \mathrm{APTS}, \mathrm{Fe}_{3} \mathrm{O}_{4} @ M A A$, and $\mathrm{Fe}_{3} \mathrm{O}_{4} @$ MIPs particles.

As shown in Figure 4, two strong adsorption peaks appeared at $589 \mathrm{~cm}^{-1}$ and $631 \mathrm{~cm}^{-1}$ for the four samples and are characteristic stretching vibration peaks generated by the group at $570 \mathrm{~cm}^{-1}$ of $\mathrm{Fe}-\mathrm{O}$ in $\mathrm{Fe}_{3} \mathrm{O}_{4}$; this indicates the presence of $\mathrm{Fe}_{3} \mathrm{O}_{4}$ in these four samples. Meanwhile, the peaks at $2856 \mathrm{~cm}^{-1}$ and $2927 \mathrm{~cm}^{-1}$ are stretching vibration peaks of $-\mathrm{CH}_{2}$, and both appeared in characteristic 


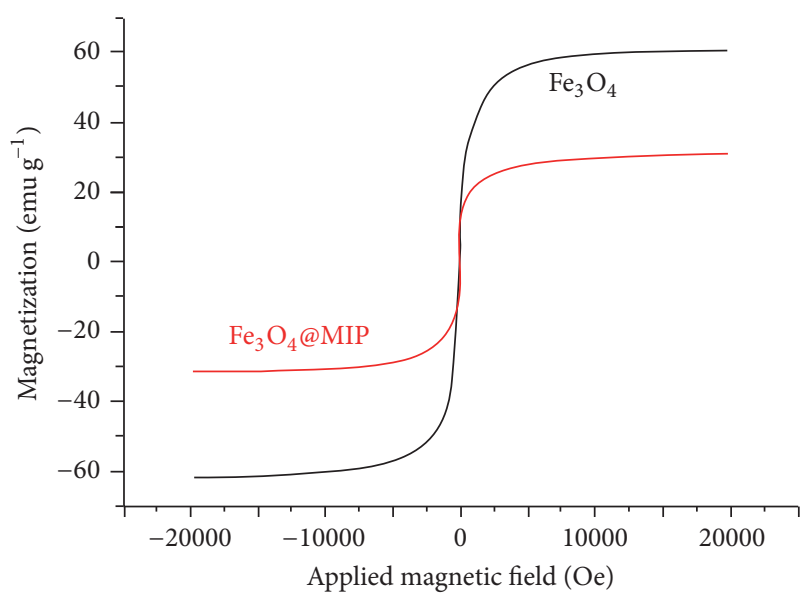

(a)

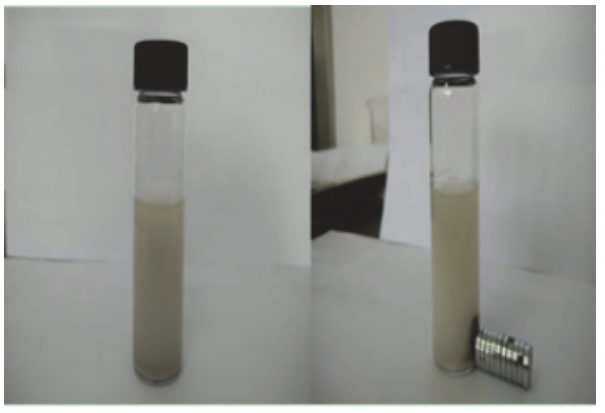

(b)

FIgURE 5: Hysteresis chart of magnetic particles (a) and reaction to external magnetic fields (b).

plots of $\mathrm{Fe}_{3} \mathrm{O}_{4} @ \mathrm{APTS}$ and $\mathrm{Fe}_{3} \mathrm{O}_{4} @ \mathrm{MAA}$ particles, which indicates successful modification with APTS. In addition, both $\mathrm{Fe}_{3} \mathrm{O}_{4} @ \mathrm{MAA}$ and $\mathrm{Fe}_{3} \mathrm{O}_{4} @ \mathrm{MIP}$ spectra showed peaks at $1735 \mathrm{~cm}^{-1}\left(\mathrm{C}=\mathrm{O}\right.$ vibration peak) and $1455 \mathrm{~cm}^{-1}(\mathrm{C}=\mathrm{C}$ vibration peak), which indicates successful modification with MAA monomers. Of these, $1735 \mathrm{~cm}^{-1}$ peak intensity in $\mathrm{Fe}_{3} \mathrm{O}_{4} @$ MIPs was significantly stronger than that of $\mathrm{Fe}_{3} \mathrm{O}_{4} @$ MAA particles. This is because $\mathrm{Fe}_{3} \mathrm{O}_{4} @$ MIPs were coated with MIP due to polymerization reaction, which leads to an increase of $\mathrm{C}=\mathrm{O}$ bonds. Meanwhile, the weak Fe-O vibration peak also provides a certain evidence for nuclearshell structure of $\mathrm{Fe}_{3} \mathrm{O}_{4} @$ MIPs, which indicates successful preparation of nuclear-shell magnetic MIPs.

3.2.4. VSM Characterization. Hysteresis graphs of $\mathrm{Fe}_{3} \mathrm{O}_{4}$ and $\mathrm{Fe}_{3} \mathrm{O}_{4} @$ MIPs particles are shown in Figure 5(a), which demonstrated that hysteresis loops of both $\mathrm{Fe}_{3} \mathrm{O}_{4}$ and $\mathrm{Fe}_{3} \mathrm{O}_{4} @ M I P s$ pass the origin, with saturation magnetizations of $60 \mathrm{emu} \mathrm{g}^{-1}$ and $30 \mathrm{emu} \mathrm{g}^{-1}$, respectively. $\mathrm{Fe}_{3} \mathrm{O}_{4} @ \mathrm{MIPs}$ saturation magnetization declined, which may be due to the coated MIP layer; this would unlikely affect the magnetic separation of $\mathrm{Fe}_{3} \mathrm{O}_{4} @$ MIPs. As shown in Figure 5(b), $\mathrm{Fe}_{3} \mathrm{O}_{4} @ M I P s$ appeared as yellow suspension particles and were dispersed in the aqueous solution, but quickly concentrating at one side of the external magnetic field upon application of an external magnetic field. Therefore, $\mathrm{Fe}_{3} \mathrm{O}_{4} @ \mathrm{MIPs}$ have strong separation characteristics.

\section{3. $\mathrm{Fe}_{3} \mathrm{O}_{4} @ M I P s$ Properties}

3.3.1. Selectivity of $\mathrm{Fe}_{3} \mathrm{O}_{4} @ M I P s$. MIPs have very high affinity and selectivity and selectively adsorb target molecules from complex samples; indeed, $20 \mathrm{mg}$ of polymers can adsorb four organotins (MBT, DBT, TBT, and TPhT $50 \mu \mathrm{gL}^{-1}$ ), as shown in Figure 6.

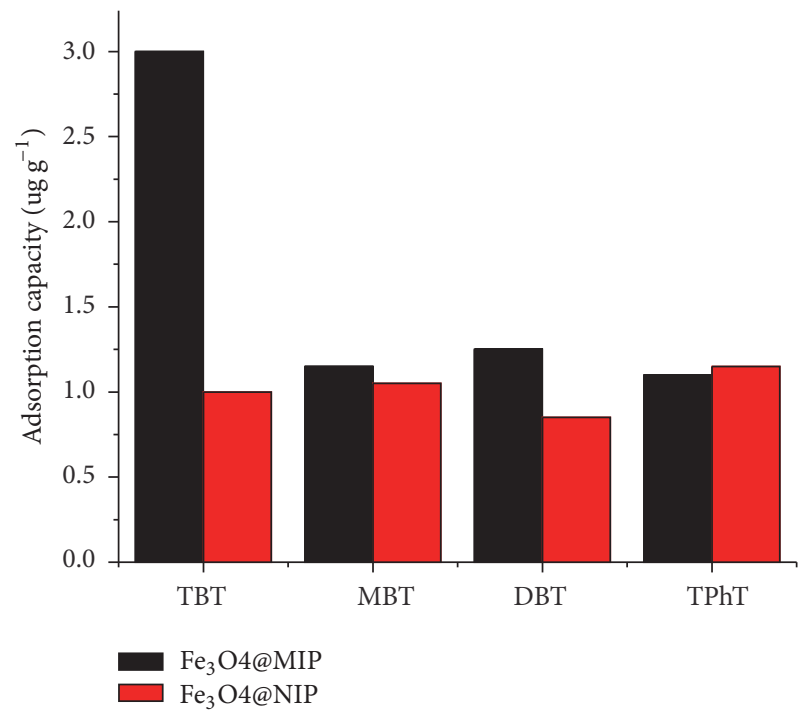

FIGURE 6: Adsorption capacity of $\mathrm{Fe}_{3} \mathrm{O}_{4} @ \mathrm{MIP}$ and $\mathrm{Fe}_{3} \mathrm{O}_{4} @ \mathrm{NIP}$ for the four organic tin compounds.

As shown in Figure 6, $\mathrm{Fe}_{3} \mathrm{O}_{4} @ \mathrm{MIPs}$ had the highest adsorption capacity to TBT, which was 3 times that of $\mathrm{Fe}_{3} \mathrm{O}_{4} @$ NIPs. Meanwhile, $\mathrm{Fe}_{3} \mathrm{O}_{4} @ M I P$ adsorption capacities for MBT, DBT, and TPhT were comparable to values obtained for $\mathrm{Fe}_{3} \mathrm{O}_{4} @$ NIPs. Thus, $\mathrm{Fe}_{3} \mathrm{O}_{4} @$ MIPs contain threedimensional voids with highly consistent spatial structure and functional group arrangement similar to TBT, thereby having a very good memory effect for TBT. This might be explained by the following: $\mathrm{Fe}_{3} \mathrm{O}_{4} @ M I P s$ are tailored for TBT, and the spatial shape and size of their three-dimensional voids exactly match TBT; the groups on the cavity surface are highly complementary to the electronic characteristics contained in TBT groups. These voids tend to have a very high specific selectivity for TBT, that is, memory function [37]. 


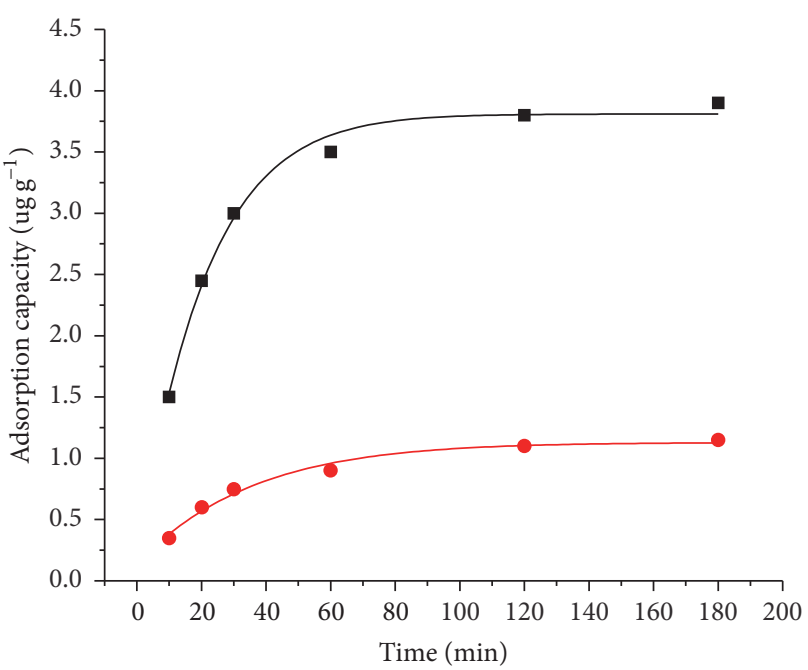

- $\mathrm{Fe}_{3} \mathrm{O}_{4} @ \mathrm{MIP}$

- $\mathrm{Fe}_{3} \mathrm{O}_{4} @ \mathrm{NIP}$

Figure 7: Adsorption kinetics of $\mathrm{Fe}_{3} \mathrm{O}_{4} @ M I P s$ and $\mathrm{Fe}_{3} \mathrm{O}_{4} @ N I P s$.

3.3.2. Adsorption Dynamics of $\mathrm{Fe}_{3} \mathrm{O}_{4} @ M I P s$. Figure 7 shows adsorption dynamics curves for $\mathrm{Fe}_{3} \mathrm{O}_{4} @ M I P$ and $\mathrm{Fe}_{3} \mathrm{O}_{4} @ \mathrm{NIPs}$, which reveal that adsorption volumes of $\mathrm{Fe}_{3} \mathrm{O}_{4} @ \mathrm{MIP}$ and $\mathrm{Fe}_{3} \mathrm{O}_{4} @$ NIPs to TBT increased with time, and equilibrium could be obtained after $1 \mathrm{~h}$. This is because shallower holes on the surface of $\mathrm{Fe}_{3} \mathrm{O}_{4} @ \mathrm{MIP}$ and $\mathrm{Fe}_{3} \mathrm{O}_{4} @$ NIPs help quickly adsorb TBT, which results in $\mathrm{Fe}_{3} \mathrm{O}_{4} @ \mathrm{MIP}$ and $\mathrm{Fe}_{3} \mathrm{O}_{4} @$ NIPs having an initial faster adsorption rate. However, after surface holes achieve adsorption saturation, transmission of TBT to internal holes of $\mathrm{Fe}_{3} \mathrm{O}_{4} @ \mathrm{MIP}$ and $\mathrm{Fe}_{3} \mathrm{O}_{4} @$ NIPs is hindered, which leads to declined adsorption rate, and adsorption equilibrium is observed after only $1 \mathrm{~h}$.

3.3.3. Adsorption Isotherm of $\mathrm{Fe}_{3} \mathrm{O}_{4} @ M I P s$. Adsorption isotherms of $\mathrm{Fe}_{3} \mathrm{O}_{4} @ \mathrm{MIP}$ and $\mathrm{Fe}_{3} \mathrm{O}_{4} @ \mathrm{NIP}$ to TBT are shown in Figure 8 .

As shown in Figure 8, the shapes of adsorption isotherms obtained for $\mathrm{Fe}_{3} \mathrm{O}_{4} @ \mathrm{MIP}$ and the corresponding $\mathrm{Fe}_{3} \mathrm{O}_{4} @ \mathrm{NIP}$ followed the Langmuir model: adsorption volume of $\mathrm{Fe}_{3} \mathrm{O}_{4} @$ MIP gradually increases with TBT concentration; meanwhile, that of $\mathrm{Fe}_{3} \mathrm{O}_{4} @ \mathrm{NIP}$ rapidly reaches saturation adsorption. In addition, for the same concentration of TBT solution (regardless the value), adsorption volume of $\mathrm{Fe}_{3} \mathrm{O}_{4} @ \mathrm{MIP}$ was significantly higher than that of $\mathrm{Fe}_{3} \mathrm{O}_{4} @ \mathrm{NIP}$, and these differences increased with the solution concentration. This is due to significant differences in spatial structures of these two polymers. $\mathrm{Fe}_{3} \mathrm{O}_{4} @ N I P$ has a weaker adsorption capacity and lacks selectivity, likely because the polar groups on its surface may nonspecifically adsorb TBT. However, $\mathrm{Fe}_{3} \mathrm{O}_{4} @$ MIP contains functional voids that match and are complementary to the spatial structure of TBT. These voids tend to remember TBT molecules and lead to strong selective adsorption capacity. Thus, the difference

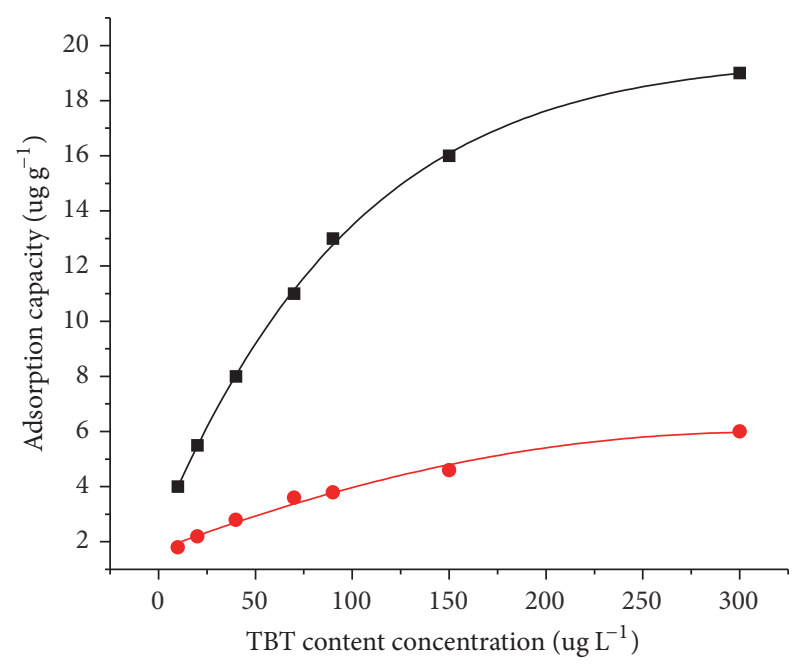

- $\mathrm{Fe}_{3} \mathrm{O}_{4} @ \mathrm{MIP}$

- $\mathrm{Fe}_{3} \mathrm{O}_{4} @ \mathrm{NIP}$

Figure 8: Adsorption isotherms of $\mathrm{Fe}_{3} \mathrm{O}_{4} @ M I P$ and $\mathrm{Fe}_{3} \mathrm{O}_{4} @ N I P$ to TBT.

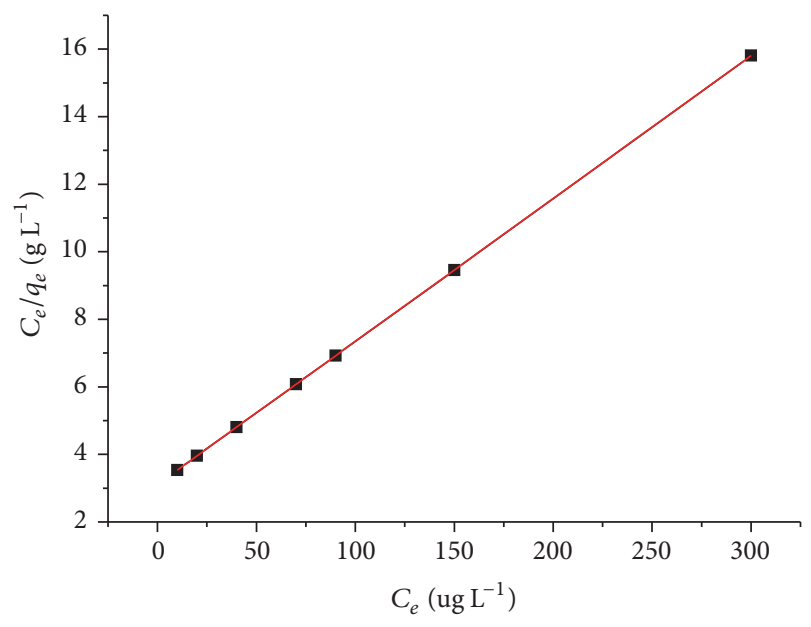

FIgURE 9: Langmuir isotherm plot of $\mathrm{Fe}_{3} \mathrm{O}_{4} @ \mathrm{MIP}$ adsorption to TBT.

in adsorption capacity of these two polymers mainly derives from the specific adsorption of these voids.

According to Langmuir isotherm equation [38], the results in Figure 9 were generated.

$$
\frac{C_{e}}{q_{e}}=\frac{1}{Q_{\max } b}+\frac{1}{Q_{\max }} C_{e},
$$

where $C_{e}$ is the balance concentration and $q_{e}$ is the balance adsorption; $Q_{\max }$ represents saturation adsorption, while $b$ is a constant. With respect to $C_{e}, C_{e} / q_{e}$ has a good linear relationship within this concentration range. From Figure 9, 
TABLE 3: Relationship between adsorption rate and time of $\mathrm{Fe}_{3} \mathrm{O}_{4} @ \mathrm{MIP}$ repeated use.

\begin{tabular}{lccccc}
\hline Repeated use time & 1 & 2 & 3 & 4 & 5 \\
Adsorption rate (\%) & 90 & 87.5 & 83 & 82.1 & 79.8 \\
\hline
\end{tabular}

TABLE 4: Recovery rates and relative standard deviations $(n=4)$.

\begin{tabular}{|c|c|c|c|c|}
\hline \multirow{2}{*}{ Sample } & \multicolumn{4}{|c|}{ Detection of TBT } \\
\hline & Background value (ng g $\left.{ }^{-1}\right)$ & Standard addition concentration $\left(\mathrm{ng} \mathrm{g}^{-1}\right)$ & Recovery (\%) & RSD (\%) \\
\hline \multirow{2}{*}{ Mussels } & \multirow{2}{*}{154} & 50 & 87.13 & 3.5 \\
\hline & & 100 & 84.36 & 2.8 \\
\hline \multirow{2}{*}{ Tegillarca granosa } & \multirow{2}{*}{216} & 50 & 95.72 & 3.2 \\
\hline & & 100 & 87.96 & 2.3 \\
\hline \multirow{2}{*}{ Large yellow croaker } & \multirow{2}{*}{ - } & 50 & 79.74 & 4.7 \\
\hline & & 100 & 83.25 & 1.3 \\
\hline
\end{tabular}

the following equation can be obtained: $C_{e} / q_{e}=3.1147+$ $0.0423 C_{e}$, where saturation adsorption of $\mathrm{Fe}_{3} \mathrm{O}_{4} @ \mathrm{MIPs}$ to TBT is $Q_{\max }=23.6 \mu \mathrm{gg}^{-1}, b=0.0136$.

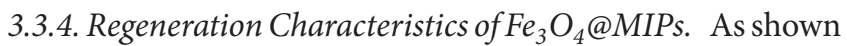
in Table 3, repeated use may lead to declined adsorption rate of $\mathrm{Fe}_{3} \mathrm{O}_{4} @ M I P s$, likely because adsorption capacity of the polymers to TBT is altered after slight swelling. However, these experimental data revealed that $\mathrm{Fe}_{3} \mathrm{O}_{4} @$ MIPs have a high strength and rigidity, with no substantial softening and dissolution during the elution regeneration process, thus presenting good repeatability.

3.4. Linear Range and Detection Limit. Detection was performed under optimal operating conditions. TBT concentration was first assessed by HPLC-ICP-MS, and linear regression equation was obtained with adsorption peak area on the $y$-axis and TBT concentration $\left(\mu \mathrm{g} \mathrm{L}^{-1}\right)$ on the $x$ axis. Then, the lowest detection rate of each marine product was calculated with $S / N=3$ as signal to noise ratio [30]. The results revealed that concentration had a good linear relationship with peak area when TBT amounts in tissue fluid of marine products ranged from $5 \mathrm{ng} \mathrm{g}^{-1}$ to $1000 \mathrm{ng} \mathrm{g}^{-1}$, with a correlation coefficient $\left(R_{2}\right)$ of $0.9995 \sim 0.9999$ and relative standard deviation equal to or smaller than $5 \%$. Meanwhile, detection rates in tissue fluids of mussels, Tegillarca granosa, and large yellow croaker were $1.0 \mathrm{ngg}^{-1}, 3.0 \mathrm{ngg}^{-1}$, and $4.0 \mu \mathrm{g} \mathrm{L}^{-1}$, respectively.

3.5. Repeatability. Testing was repeated 6 times by injecting the same concentration of TBT, and a relative standard deviation of $1.3 \%$ was obtained, indicating a good repeatability of the analysis method on the instrument used.

3.6. Analysis of Specimens. Marine product specimens were treated using the abovementioned methods, followed by separation and injection. Then, TBT concentrations in the concentrated specimens were tested by HPLC-ICP-MS under optimal conditions and recovery rates were calculated (Table 4). Indeed, recovery rates for the specimens ranged from $79.74 \%$ to $95.72 \%$, with relative standard deviations of $1.3 \%-4.7 \%$, suggesting that this method has very good accuracy and precision and can be applied for the determination of TBT in marine products.

3.7. Summary of Detection Methods. In terms of molecular imprinting technique based analysis methods for the detection of organic tin compounds, we compared previous ones to that described in this study, and the results are shown in Table 5 .

\section{Conclusion}

Using the surface molecular imprinting technique, we successfully prepared $\mathrm{Fe}_{3} \mathrm{O}_{4} @$ MIPs that specifically identified TBT by employing TBT as template molecules, $\mathrm{Fe}_{3} \mathrm{O}_{4} @ \mathrm{MAA}$ as functional monomers, EGDMA as the cross linking agent, AIBN as the initiator, and acetonitrile as the porogen. Compared with conventional molecular imprinting polymers, this polymer showed significant selective adsorption and can be rapidly separated by an external magnetic field, with a shortened pretreatment time. In this study, we confirmed that, with magnetic MIP as adsorbent, TBT could be assessed by HPLCICP-MS. In addition, with marine products as matrixes, the lowest detection rate and linear range for this method were $1.0 \mathrm{ng} \mathrm{g}^{-1}$ and $5.0 \mathrm{ngg}^{-1}-1000 \mathrm{ng} \mathrm{g}^{-1}$, respectively. Finally, this method was used to analyze mussels, Tegillarca granosa, and large yellow croaker, with recovery rates of 79.74-95.72\% and RSD values of $1.3 \%-4.7 \%$.

\section{Competing Interests}

The authors declare that there is no conflict of interests regarding the publication of this paper. 


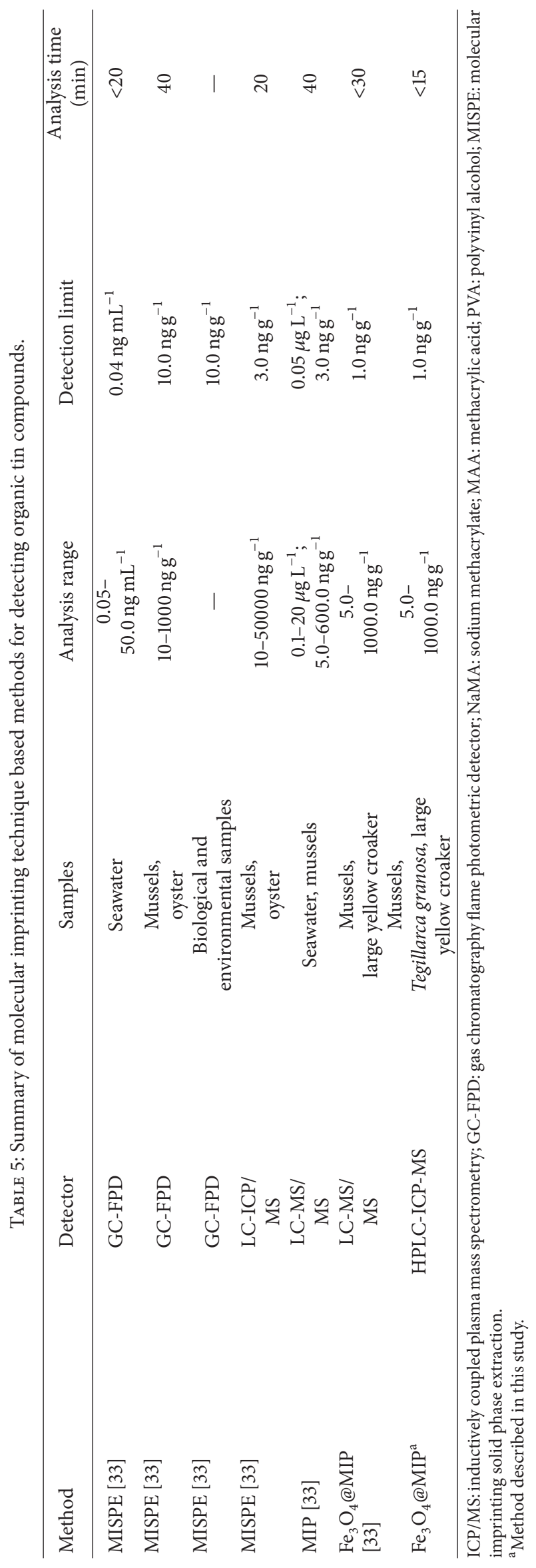




\section{Authors' Contributions}

Hua Yang and Huien Zhang contributed equally to this work and should be considered co-first authors. Shi Da Chen and Lijun Liu assisted in data processing and production of magnetic molecular imprinting polymers in the paper.

\section{Acknowledgments}

This research was funded by the Ministry of Science and Technology of Chinese People's Republic Spark Plan Project (Grant no. 2011GA701001), Zhejiang Province Public Technology Research Projects (Grant no. 2016C32068), and Ningbo City Science Foundation (Grant nos. 2015C10018 and 2016C10009). This work was financially supported by the Projects of Science and Technology Ministry of China (2015BAD17B02-3) and the K.C. Wong Magna Fund in Ningbo University.

\section{References}

[1] M. Hoch, "Organotin compounds in the environment-an overview," Applied Geochemistry, vol. 16, no. 7-8, pp. 719-743, 2001.

[2] Q. Xie, C. Shuo, X. Daming et al., "Migration and conversion of organotin pollutants in marine sediments," Marine Environmental Science, vol. 14, no. 4, pp. 21-26, 1995.

[3] Q. Xie and Z. Yang, "Studies on biological silicon-containing organic tin compounds," Silicone Materials and Application, no. 5, pp. 1-7, 1994.

[4] W. Chunhua, L. Youpei, and R. Daofeng, "Effects of dibutyltin dilaurate on exposure on workers' health," Journal of Bengbu Medical College, vol. 22, no. 2, pp. 118-119, 1997.

[5] W. Shanshan and F. Liu, "Toxic effect of organic tin compounds and its influencing factors," Journal of Safety and Environment, vol. 5, no. 3, pp. 12-15, 2005.

[6] J. Qin, S. Xia, and S. Pengfei, "Progress of detection of organotin in marine products or seawater," Chemical Agent, vol. 31, no. 9, pp. 693-696, 2009.

[7] P. F. Seligman, A. O. Valkirs, and R. F. Lee, "Degradation of tributyltin in San Diego Bay, California, waters," Environmental Science \& Technology, vol. 20, no. 12, pp. 1229-1235, 1986.

[8] S. M. Evans, T. Leksono, and P. D. McKinnell, "Tributyltin pollution: a diminishing problem following legislation limiting the use of TBT-based anti-fouling paints," Marine Pollution Bulletin, vol. 30, no. 1, pp. 14-21, 1995.

[9] M. D. Müller, L. Renberg, and G. Rippen, "Tributyltin in the environment-sources, fate and determination an assessment of present status and research needs," Chemosphere, vol. 18, no. 9-10, pp. 2015-2042, 1989.

[10] C. Alzieu, "Tributyltin: case study of a chronic contaminant in the coastal environment," Ocean and Coastal Management, vol. 40, no. 1, pp. 23-36, 1998.

[11] J. Gui-bin, N. Zhe-ming, W. Shun-rong, and H. Heng-bin, "Organic mercury speciation in fish by capillary gas chromatography interfaced with atomic absorption spectrometry," Fresenius' Zeitschrift für Analytische Chemie, vol. 334, no. 1, pp. 27-30, 1989.

[12] W. M. Dirkx and F. C. Adams, "Pentylated organotin standards: guidelines for their synthesis, purity control and quantification,"
Applied Organometallic Chemistry, vol. 8, no. 7-8, pp. 693-701, 1994.

[13] R. Łobifiski, W. M. R. Dirkx, M. Ceulemans, and F. C. Adams, "Optimization of comprehensive speciation of organotin compounds in environmental samples by capillary gas chromatography helium micro wave-induced plasma emission spectrometry," Analytical Chemistry, vol. 64, no. 2, pp. 159-165, 1992.

[14] M. D. Mueller, "Tributyltin detection at trace levels in water and sediments using GC with flame-photometric detection and GCMS," Fresenius' Zeitschrift für Analytische Chemie, vol. 317, no. 1, pp. 32-36, 1984.

[15] Z.-H. Yu, J. Zhang, and X.-R. Wang, "Speciation analysis of organotin compounds in sediment by hyphenated technique of high performance liquid chromatography-inductively coupled plasma mass spectrometry," Chinese Journal of Analytical Chemistry, vol. 39, no. 4, pp. 544-547, 2011.

[16] X. Lei, Application of ICP-MS and Its Combination Techniques in Analyzing Speciation of Tin in Marine Products and Water Samples, Department of Chemistry, College of Science, Nanchang University, Nanchang, China, 2012.

[17] J. Guibin, X. Fuzheng, and H. Bin, "Progress in determination of organic tin compounds," Marine Environmental Science, vol. 18, no. 3, pp. 61-66, 1999.

[18] Z.-H. Yu, M. Jing, X.-R. Wang, D.-Y. Chen, and Y.-L. Huang, "Simultaneous determination of multi-organotin compounds in seawater by liquid-liquid extraction-high performance liquid chromatography-inductively coupled plasma mass spectrometry," Spectroscopy and Spectral Analysis, vol. 29, no. 10, pp. 28552859, 2009.

[19] C. Lihua, Determination of Different Forms of Organic Tin Compounds in Foods with High Performance Liquid Chromatography, Series Mass Spectrometry, Department of Chemistry, College of Science, Nanchang University, Nanchang, China, 2013.

[20] Z. Yongjun, Separation and Extraction of Functional Components from Garlic with Molecular Imprinting Technique and Studies of Pharmacological Activities, College of Medicine, Ocean University of China, Qingdao, China, 2012.

[21] M. Zhang, Molecular Imprinting Polymers and Their Application in Separation Analysis, Huaqiao University, Fujian, China, 2005.

[22] Z. Zheng, Synthesis of Organotin Molecular Imprinting Polymer and Its Application in Marine Environmental Monitoring, Huaqiao University, Fujian, China, 2006.

[23] H. Wang, H. Yan, M. Qiu, J. Qiao, and G. Yang, "Determination of dicofol in aquatic products using molecularly imprinted solid-phase extraction coupled with GC-ECD detection," Talanta, vol. 85, no. 4, pp. 2100-2105, 2011.

[24] B. Liu, M. Han, G. Guan, S. Wang, R. Liu, and Z. Zhang, "Highly-controllable molecular imprinting at superparamagnetic iron oxide nanoparticles for ultrafast enrichment and separation," Journal of Physical Chemistry C, vol. 115, no. 35, pp. 17320-17327, 2011.

[25] Y. Zhang, R. J. Liu, Y. L. Hu, and G. K. Li, “Microwave heating in preparation of magnetic molecularly imprinted polymer beads for trace triazines analysis in complicated samples," Analytical Chemistry, vol. 81, no. 3, pp. 967-976, 2009.

[26] Y. Yu, Y.-Y. Zhuang, and Z.-H. Wang, "Adsorption of watersoluble dye onto functionalized resin," Journal of Colloid and Interface Science, vol. 242, no. 2, pp. 288-293, 2001.

[27] L. C. A. Oliveira, R. V. R. A. Rios, J. D. Fabris, K. Sapag, V. K. Garg, and R. M. Lago, "Clay-iron oxide magnetic composites for 
the adsorption of contaminants in water," Applied Clay Science, vol. 22, no. 4, pp. 169-177, 2003.

[28] L. C. A. Oliveira, D. I. Petkowicz, A. Smaniotto, and S. B. C. Pergher, "Magnetic zeolites: a new adsorbent for removal of metallic contaminants from water," Water Research, vol. 38, no. 17, pp. 3699-3704, 2004.

[29] A. Denizli, R. Say, and E. Pişkin, "Removal of aluminium by Alizarin Yellow-attached magnetic poly(2-hydroxyethyl methacrylate) beads," Reactive and Functional Polymers, vol. 55, no. 1, pp. 99-107, 2003.

[30] I. Šafařík, M. Šafaříková, and V. Buřičová, "Sorption of water soluble organic dyes on magnetic poly(oxy-2,6-dimethyl-1,4phenylene)," Collection of Czechoslovak Chemical Communications, vol. 60, no. 9, pp. 1448-1456, 1995.

[31] Y. Chaoxiong, W. Jinyuan, and D. Guangjun, "A study on magnetic resins-cellulose base polyurethane resin," Ion Exchange and Adsorption, vol. 10, no. 6, pp. 523-537, 1994.

[32] K. Yefang, Superparamagnetic $\mathrm{Fe}_{3} \mathrm{O}_{4}$ Nano Immobilized Enzyme and Its Application in Biosensors, Jiangnan University, Wuxi, China, 2012.

[33] Z. Shanshan, Molecular Imprinting Technique Based Methods in Detecting Trace Amount of Organotin in Marine Products and Seawater, University of Ningbo, Ningbo, China, 2013.

[34] Z. Hong, Z. Ming, P. Zhiquan, and H. Qimao, "Synthesis and characterization of functionalized $\mathrm{Fe}_{3} \mathrm{O}_{4}$ and its adsorption to calcium ions," Journal of Wuhan Institute of Technology, vol. 35, no. 4, pp. 14-20, 2013.

[35] H. Xiaojin, T. Tianwei, Q. Yizheng, L. Wei, and L. Qing, "Preparation of spherical chitosan resin and its adsorption properties," Ion Exchange and Adsorption, vol. 16, pp. 47-53, 2000.

[36] Y. Li, X. Li, J. Chu, C. Dong, J. Qi, and Y. Yuan, "Synthesis of core-shell magnetic molecular imprinted polymer by the surface RAFT polymerization for the fast and selective removal of endocrine disrupting chemicals from aqueous solutions," Environmental Pollution, vol. 158, no. 6, pp. 2317-2323, 2010.

[37] J. Saloni, P. Lipkowski, S. S. R. Dasary, Y. Anjaneyulu, H. Yu, and G. Hill Jr., "Theoretical study of molecular interactions of TNT, acrylic acid, and ethylene glycol dimethacrylate-elements of molecularly imprinted polymer modeling process," Polymer, vol. 52, no. 4, pp. 1206-1216, 2011.

[38] S. Wang, C. W. Ng, W. Wang, Q. Li, and L. Li, "A comparative study on the adsorption of acid and reactive dyes on multiwall carbon nanotubes in single and binary dye systems," Journal of Chemical \& Engineering Data, vol. 57, no. 5, pp. 1563-1569, 2012. 

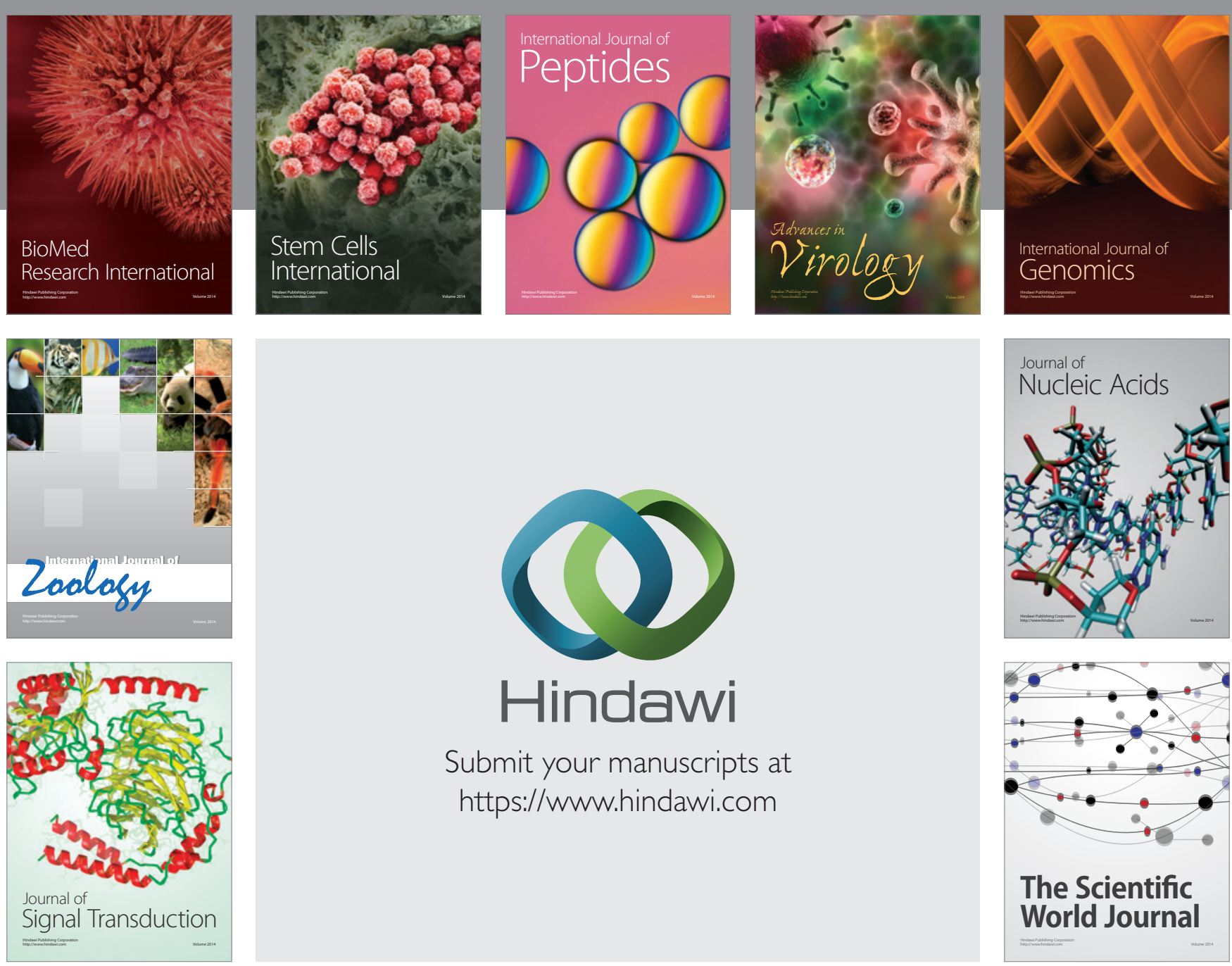

Submit your manuscripts at

https://www.hindawi.com
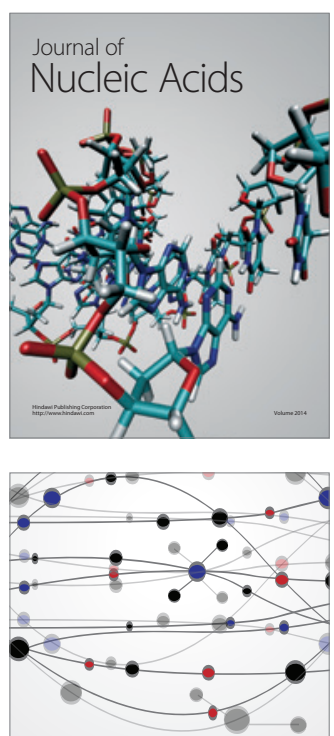

The Scientific World Journal
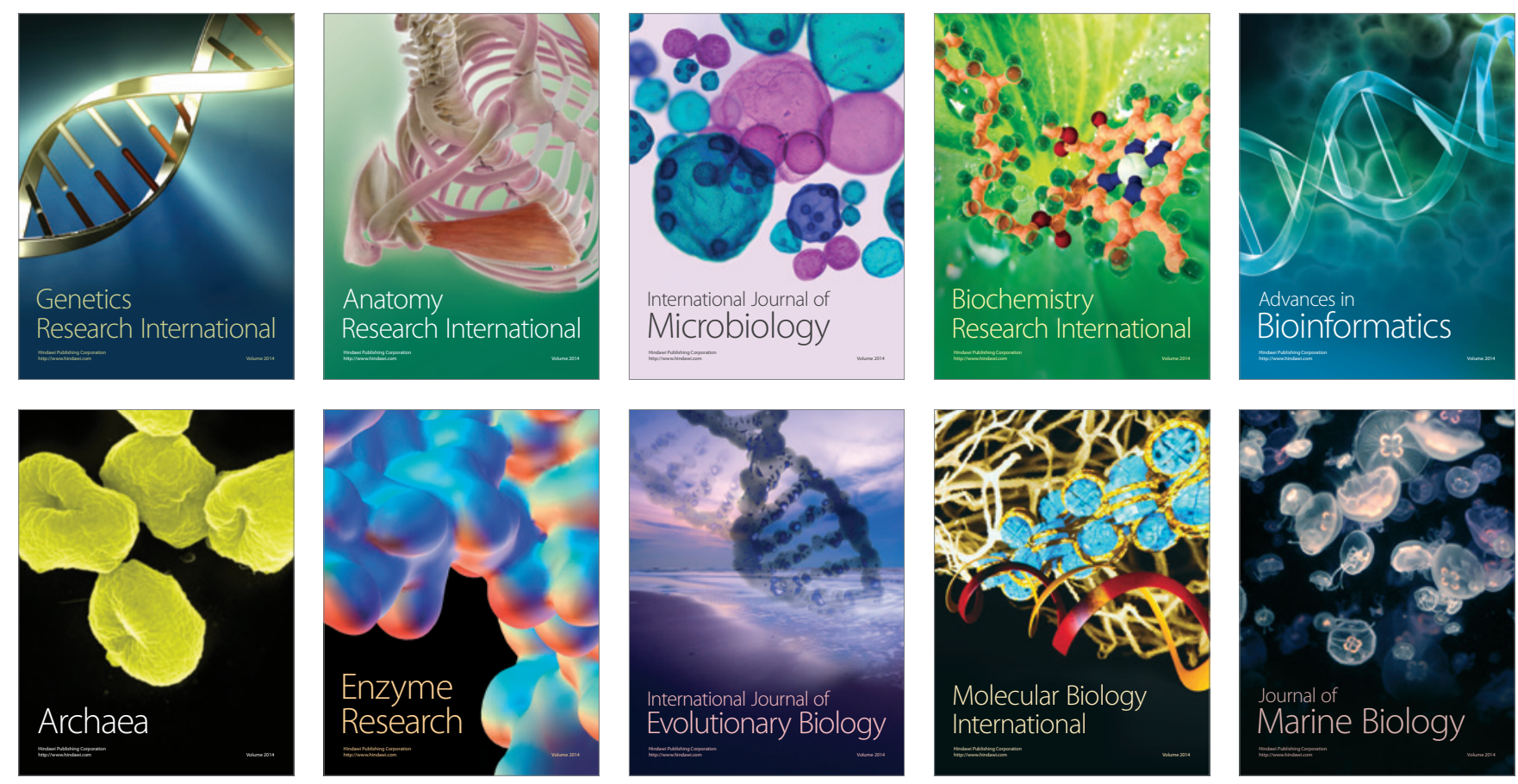